\title{
Route Selection Decision-Making in an Intermodal Transport Network Using Game Theory
}

\author{
Lucija Bukvić $^{1}$, Jasmina Pašagić Škrinjar ${ }^{1}$, Borna Abramović ${ }^{1, *(\mathbb{D}}$ and Vladislav Zitrický ${ }^{2}$ (D) \\ 1 Faculty of Transport and Traffic Sciences, University of Zagreb, 10000 Zagreb, Croatia; \\ lbukvic@fpz.unizg.hr (L.B.); jpasagic@fpz.unizg.hr (J.P.Š.) \\ 2 Faculty of Operation and Economics of Transport and Communications, University of Zilina, \\ 01026 Zilina, Slovakia; vladislav.zitricky@fpedas.uniza.sk \\ * Correspondence: borna.abramovic@fpz.hr; Tel.: +385-1-245-7702
}

check for updates

Citation: Bukvić, L.; Pašagić Škrinjar, J.; Abramović, B.; Zitrický, V. Route Selection Decision-Making in an Intermodal Transport Network Using Game Theory. Sustainability 2021, 13, 4443. https://doi.org/10.3390/ su13084443

Academic Editor: Tomio Miwa

Received: 9 March 2021

Accepted: 13 April 2021

Published: 15 April 2021

Publisher's Note: MDPI stays neutral with regard to jurisdictional claims in published maps and institutional affiliations.

Copyright: (c) 2021 by the authors. Licensee MDPI, Basel, Switzerland. This article is an open access article distributed under the terms and conditions of the Creative Commons Attribution (CC BY) license (https:// creativecommons.org/licenses/by/ $4.0 /)$.

\begin{abstract}
Traveling through a transport network, or ordering and delivering packets, involves fundamental decision-making processes which can be approached by game theory: Rather than simply choosing a route, individuals need to evaluate routes in the presence of the congestion resulting from the decisions made by themselves and everyone else. In this paper, a game theory model for resolving route choices in transport network graphs is used. In the process of doing this, discovering a rather unexpected result known as Braess's paradox, which shows that adding capacity to a network can sometimes actually cause congestion and an increase in transport costs. The decisions are made by non-cooperative players in a game theory environment known as prisoner's dilemma. These methods are used to analyze routing problems by competing logistics operators on the transport network consisting of three Eastern Adriatic ports and an intermodal terminal in Budapest. The congestion game can be used in route selection regarding a decrease in transport costs for the carriers who are considered as rational players choosing the most sustainable solution.
\end{abstract}

Keywords: nash equilibrium; rational; decision-making; Braess's paradox; prisoner's dilemma; price of anarchy; transport cost; TEU

\section{Introduction}

The Nobel Memorial Prize in Economic Sciences (commonly referred to as the Nobel Prize in Economics) in 1994 went to two mathematicians and one economist: (1) John Forbes Nash, (2) Reinhard Selten, and (3) John Charles Harsany. The committee reasoned that an advanced game theory and its application in economic science has significant utility for professionals and the general public. We can declare that today's science is unimaginable after this great success in accepting game theory without using different game theory approaches. As known, a game consists of a set of players, a set of strategies for each player, and a utility function for each player, which is defined based on combinations of strategies by all players. It is important to emphasize that each player's choice can affect not only them but also the other players [1].

John Nash proved that there is a balance in games involving $\mathrm{n}$ players. Or, to put it more precisely, he proved that every finite game of strategy (normal) form has an equilibrium mixed strategy. Nash's equilibrium is achieved by seeking each player's best response to his opponent's given actions (strategies) [2].

The concept of equilibrium is borrowed from the natural sciences and invokes the connotation of the game of equilibrium between opposing forces. However, since we do not have general convergence results, even if we agree with the model assumption, there is no guarantee that what we observe actually matches the equilibrium. Thus, the first player will often play irrationally and choose the second strategy to make sure it will not be a big loss. 
Nash has proven that every finite non-cooperative game has a solution. The solution does not have to exist in the form of a pure strategy. It does not have to be unique, and it does not have to be effective in Pareto's sense. There are many examples in game theory that proves Nash equilibrium does not have to be unique: Pure coordination, the battle of the sexes, deer hunting, etc. [3]. Soon it was stated in the literature that the game equilibrium may not necessarily be the best choice, for example, in the game of "prisoner's dilemma" [4]. The basic premise of Nash equilibrium is that player decisions are rational. Modern game theory is actively addressing the problem of bounded rationality [5].

Albert W. Tucker formalized the game with prison sentences and payouts, and he named it prisoner's dilemma. The prisoner's dilemma as a game has attracted many game theory scholars' attention because it is applicable in various scientific fields. To illustrate this situation, let us consider a two-player game with a sum different from zero (bimatrix game). Make two strategies available to the first player and also two strategies to the second player. It is easy to determine equilibrium by game payouts if, according to each strategy of the first player, the second leaves with the best possible strategy [4].

Game theory models are based upon the mathematical knowledge and intuition of a researcher about what is relevant for the specific situation and what is not [1]. A successful application of such a model in analyzing certain transport issues is shown through this paper's analyzed problem. The initial assumptions about players, or carriers, are that they are not in complete conflict in the process of determining routes through the game theory approach. An example from three seaports is observed: From Trieste, Koper, and Rijeka, cargo should be transported to the intermodal distribution center in Budapest. Conflicts, in this case, arise when a large number of transport network users create congestion using the same part of the transport network, which has the lowest transport costs for carriers. Coordinated use of the network can relieve congestions and increase overall flow by transferring from road to the railway, which results in a shorter total retention time for all network users or a reduction in total costs [6].

This paper shows that by choosing the cheapest route, we can influence congestion, and the estimated costs will be significantly higher. The selection of the optimal route must be chosen in a way that follows the decisions of other carriers, and game theory has proven to be an excellent tool for such a decision-making process. Game theory is based on the fact that the result of the game does not depend on only one player, which we see in the example shown. By changing the route in order to reduce transport costs, an individual carrier actually increases the estimated costs and increases the costs of other carriers that have already used that route of the transport network. By applying Nash Equilibrium, we obtain an optimal route plan for all the railway undertakings that have been analyzed as each of their selfish game results in increases in cost. All of the above points to the importance of analyzing all stakeholders in the transportation system at a particular location in order to determine the cheapest route. Analyzing only the price of the trip, the estimated costs will not be accurate.

Most scientific papers use mathematical models to determine routes and choose the optimal path, but authors do not analyze the selection of routes of other players or competitors. Thus the optimal path can be different in a real environment, as shown in this paper.

Perfectly rational and intellectually equal partners are what separates game theory from practice. The theory completely disregards players' individuality, even though knowledge, intelligence, and character traits affect the final negotiation outcome in real-world situations. The theoretical solution is based solely on the specificity of a conflict situation. Making business decisions in a real-world environment is connected with bounded rationality. Researchers apply game theory to business systems and model assumptions about player limitations related to player memory, their perception, knowledge, ability to process information, and then analyze how these limitations affect player behavior and game score. Game theory must include psychological elements in its framework to allow a more realistic interpretation of the decision maker's actual choice. The decision must be 
based on a solid empirical basis. Psychological studies related to decision-making in game theory should serve as a basis for establishing regularity in participants' behavior in the game and a deeper understanding of bounded rationality.

\section{Literature Review}

As stated previously, game theory enters the decision-making process step by step and in the transport planning process. Pinakpani et al. [7], in their research for the pollution segment in the collaborative game, use a theoretical approach, as Shapley value is proposed for improved decision-making. The research proposes the need and method to enhance hinterland connectivity using a scalable greedy algorithm tested with coal and bulk cargo real-time data. Interesting results are found in research by Mahmoudi et al. [8], who developed game-network data envelopment analysis (DEA) considering the transport system's sustainability. When constructing the game strategy, the authors took into account the following aspects of (1) economic, (2) social, and (3) environmental analyses in the transport system. The proposed model was applied to a real case study of an urban transport network. Zhang et al. [9] analyzed a typical water-rail-road (WRR) intermodal transport network. Considering the decentralized decision-making process, it was interpreted that the incentive contract design problem for the WRR intermodal transport could be presented as a Stackelberg game. To comply with the results, a simulation example investigated the impact of asymmetric information on the optimal time-based incentive contracts and identified the value of the WRR intermodal transport value. A novel approach using game theory by Bekius et al. [10] has been introduced to compare different outcomes in a unique development case. In large infrastructural systems, the decision-making process is too complex. The authors also concluded that those game theory concepts explained the different outcomes in a Dutch railway sector's unique development case. The conclusion stated clearly that the game theory approach could reveal the hidden actor and context dynamics of the process, which provides an action perspective. In research that tackles car travel challenges, Dogterom et al. [11] have reviewed empirical research and in-depth analysis of relevant behavioral approaches. A game theory approach presents a helpful tool for studying multiple decision-maker's choices in a framework in which payoffs are dependent on the choices of others included in the market. In a survey of intelligent transport systems, Rizk et al. [12] main focus was on the decision-making process. The main reasons for that approach were an integral part of intelligent agents and multi-agent systems that allow such systems to accomplish increasingly complex tasks. In this survey, the authors have investigated different approaches and game theory to value intelligent transport systems' different components. Butsenko [13] conducted detailed research regarding investment planning optimization based on the game theory approach. The algorithm combines the methods of matrix games. The methodology is tested on the example of the passenger transport enterprise where obtained results show the effectiveness of using the game theory approach for optimizing the management of investment processes. Another approach for game theory has been introduced by Huang [14] for bidding decisions in engineering. The approach is based on the static game theory. In the proposed model, game participants' effectiveness and the objective function are the main constraints as price quotation characteristics. The results can give a better understanding of investment decisions in engineering management. Pašagić Škrinjar et al. [15] present how additional information is included in the game theory approach in order to make the optimal decision. In general, the game theory approach of selecting the destination terminal has been processed. The numerical example has been presented for a better explanation of the selection procedure for urban transport planning. Complex research about non-cooperative game theory's applicability in transport analysis has been made in Hollander and Prashker [16]. This research presents insights concerning the relations between transport models and games. In addition, the difference was between games that make a conceptual contribution and games suitable for the application. One of the interesting conclusions is that symmetric game structures make remarkable observations but often do not support actual decision- 
making. Very often, in practical logistics, business players are using different auction systems. In research, Gansterer and Hartl [17] investigate the combinatorial auction system with special attention to the first step of auction where it is necessary that carriers have to decide on the set of requests offered to the auction. Their research shows that a Prisoners' Dilemma can be constructed, but the computational study revealed the opposite. The research participants reduced their share of gained collaboration profits if they deviate from the jointly agreed selection rule. This can be an important and insightful finding of the practical applicability of auction-based trading mechanisms in collaborative transportation. Di Febbraro et al. [18] proposed a modeling framework for cooperation in intermodal freight transport chains as multi-actor systems. They developed a discrete event model, optimizing the system on a rolling horizon basis to account for intermodal freight transport operations dynamics. The modelling framework is developed based on the possibility of exchanging information in real-time and afterward forming freight corridors, along which all freight movements are planned and monitored. The result of research that it is possible to achieve a minimum delay in the distribution of freight in the whole network, without or with little increase in transport costs. In intermodal transport, dry ports are playing a crucial role in future development [19]. The new focus on strategic investment of the port-hinterland container transport network is resilience. Chen et al. [20] conducted research using a network game theory approach to investigate players' strategic investment in a port-hinterland container transport network to enhance network resilience to man-made unconventional emergency events by reducing vulnerability. Their research focused on complex business relationships among players in their strategic investment decisions and behavior. They proposed some interesting, useful managerial insights to establish a port-hinterland container transport network that was less vulnerable and more resilient to a potential man-made unconventional emergency. Jamali and Rasti-Barzoki [21] did interesting research combining decreasing carbon emission and delivery time using a game-theoretic approach for using it in supply chain management. They developed three scenarios: (1) Centralized game is considered in which the manufacturers cooperate, (2) decentralized game where manufacturers are leaders, and the other players are followers, (3) decentralized game where the third-party logistics is the leader, and the other players are followers. The results indicate that competition between the supply chain members is necessary to create a sustainable supply chain because cooperation among the supply chain members leads to a decrease in the supply chain's sustainability indices.

With a comprehensive analysis of previous literature and interesting conclusions in each literature, further research in the game theory approach could be a novel and suitable step in different transport planning processes. In our research, we apply the game theory approach for decision-making analyzing sustainable routing problems for the intermodal transport network.

\section{Rational Choice in Game Theory Environment}

As stated earlier, the main premise of the Nash equilibrium is the rational choice of players. The question is, what is meant by rational? Most game theory authors link rational decision-making to feasibility and desirability. In the literature, separating feasibility from desirability would be rational for most people [22].

Rational decision-making is not completely clearly defined, thus this concept should be given special attention as a fundamental concept in game theory.

In most game theory textbooks, the key term is rational when opposing players considering other players' actions, and each player chooses its best strategy (the one that brings the greatest benefit). Classical decision theory makes no distinction between maximizing utility and minimizing harm as objectives of the function.

Providing the following definition of rationality: [23] "a player is rational if he or she has properly defined goals (or preferences) from a set of possible outcomes and applies the best possible strategy to achieve those goals." 
It could be said that the term rational means that each player has a consistent set of values or payoffs for all possible outcomes and chooses a strategy that best serves his interests, or the game is rational when players choose a strategy to maximize their payoffs safely.

In game theory, the well-known game is a prisoner's dilemma. What is so striking about this game is the fact that each player does what is rational to itself, but the result does not turn out to be rational for them as a group.

The rational choice might be called constraint optimization in "mathematical language," a selected variant that maximizes utility (goal or payoff function), considering the constraints given.

It can be observed that for a well-defined constraint optimization problem, there can be a large number of constraints that collectively define the achievable set but only one objective function (utility function maximized or damage function minimized). Of course, there are many goals and criteria by which decisions are evaluated in real life. However, until these criteria are reduced to a single objective function, the goals are not well defined for decision-makers.

It is important not to forget the difference between feasibility and desirability. The mathematical model may be useful to take some utility criteria as "constraints," but this should be considered a heuristic that helps reduce the set of relevant variants and simplifies the utility function's specifications [22].

Constraints regarding this study can be seen in container carriers who choose terminals based on their productivity and, consequently, shorter stay in the port [24]. At the same time, ships are increasing in size, with more than double in capacity than a decade ago. Such ship daily operational costs are also double; carriers and terminal operators follow the same goal of a ship's minimal stay in the system. Very often, such requests are included in commercial agreements between carriers and terminal operators [25].

\section{Decision-Making Process in Game Theory}

Deciding in uncertain conditions is a very important factor in today's business processes of an individual company. Due to lack of information and the unknown future state of the environment, decision-makers find themselves very ungrateful. Applying different decision criteria facilitates the decision-making process.

Risk decision-making involves a situation in which several relevant conditions are likely to be known to decision-makers (if not known, it is assumed that they can be reasonably estimated with reasonable probability).

The criterion for choosing a variant in such situations is often the expected value of utility. In game theory, deciding on conditions of uncertainty is a game against nature.

In the mid-eighteenth century, Daniel Bernoulli proposed the idea that people maximize expected utility rather than value. He suggested that if we wanted to predict human behavior, it would be better for us to calculate the expected value of the monetary value utility rather than the expected value of choice [22]. Putting utility into a weighted sum allows for much more freedom. Maximizing expected utility can explain much more than maximizing expected payoffs.

Authors [26] claim that risk aversion is the predominant occurrence in the gain domain and risk-seeking is in the loss domain. They also claimed that a reluctance to lose could make people risk a greater loss accordingly to reconciling with a safe smaller loss.

Prisoner's dilemma, as the most well-known and fundamental problem of game theory, shows a situation in which cooperation between two players is impossible even when it is in their interest in cooperation to be realized. This game's idea and structure were devised in the 1950s by Merrill Flood and Melvin Dresher as part of RAND Corporation's research to apply to a global nuclear strategy.

In the original game of the prisoner's dilemma, police question two suspects for involvement in a felony, but there is not enough evidence to charge any of them. The tests are performed in separate rooms, and neither of them knows how the test of the other 
is progressing. Since the moves are hidden, a game model with simultaneous moves is suitable even when the tests are not performed simultaneously.

The suspects have two options, admit or deny involvement in the crime. If none of the suspects pleads guilty, the police cannot prove their guilt, but they can charge them with a minor crime, for which they have evidence. Prisoners are in doubt because if one of them confesses and the other does not, the one who confessed will be released, while the other who did not confess will receive a maximum sentence of 10 years in prison. If no one admits to the crime, everyone will get a year in prison for a minor offense. If both confess to the crime, each will receive 5 years in prison. Everyone is in a dilemma about whether to admit a crime or not. If this is understood as a game, the question that arises is how the suspects will behave [3].

The prisoner's dilemma says that psychologists should be included in game theory decision-making processes. The problem with the prisoner's dilemma is that the prisoners are not loyal to each other, they are distrustful and selfish, and the problem could be solved in favor of prisoners if they only believed one another a little bit without thinking about selfish motives.

The main point of the prisoner's dilemma is that there are numerous social interaction situations in which individual rationality does not lead to group rationality. There are a number of examples in the social sciences that the desire could not have been achieved-it was not feasible because of human nature.

When playing against nature, it is usually assumed that every state of nature is equally likely. The goal for the player playing against nature may minimize the risk in a way to ensure the highest possible reliable profit. Risk-based decision-making is realistic to expect in everyday life, and risk can most easily be defined as the product of the probability of an observed event and the quantitative value of that event. The prisoner's dilemma with the investigated suspects is shown in the following example, where the first players' strategies are rows and the second players' strategies are columns [15].

Table 1 shows three payoff matrices:

Table 1. Prisoner's dilemma, payoff matrices in prison years.

\begin{tabular}{ccccccccc}
\hline & (a) & \multicolumn{9}{c}{ (b) } & \multicolumn{3}{c}{ (c) } \\
\hline & admit & deny & & admit & deny & & admit & deny \\
admit & $(1,1)$ & $(10,0)$ & admit & $(0.20,0.20)$ & $(8,0)$ & admit & $(0.8,0.8)$ & $(2,0)$ \\
deny & $(0,10)$ & $(5,5)$ & deny & $(0,2)$ & $(4,4)$ & deny & $(0,8)$ & $(1,1)$ \\
\hline
\end{tabular}

(a) Payoff matrix (years of imprisonment) for different combinations of the first and second player strategies.

(b) The first player assumes a probability of $20 \%$ where the second player will choose:

i. The "Deny" strategy (payoff matrix in Table $1 \mathrm{~b}$ favors to Nash equilibrium),

ii. "admit-admit "equilibrium.

(c) If the first player is sure with a probability of $80 \%$, the second player will choose:

i. The "Deny" strategy (the payoff matrices in Table 1c pulls other player),

ii. The "Deny" strategy.

That kind of decision-making can be used in transport network planning by adding ponders, which can be generated by multiplying base parameters with capacity, distances, traveling time, etc. Adding extra capacity to the transport network when the moving entities (players) selfishly choose their route can reduce overall performance.

\subsection{Transport Network Graph in Normal and Extensive Form}

In the literature, the appearance of reduced performance is called Braess's paradox, credited to the German mathematician Dietrich Braess [27]. The cause in reduction is that such a system's Nash equilibrium is not necessarily an optimal result. 
The paradox is stated as follows [28]: "For each point of a road network, let there be given the number of cars starting from it and the destination of the cars. Under these conditions, one wishes to estimate the distribution of traffic flow. Whether one street is preferable to another depends not only on the quality of the road but also on the density of the flow. If every driver takes the path that looks most favorable to him, the resultant running times aren't minimal. Furthermore, it is indicated by an example that an extension of the road network may cause a redistribution of the traffic flow that results in longer individual running times".

Figure 1 is a representation of a transportation network by a directed graph: Consider the edges to be railways and the nodes to be ports and terminals where you can get on or off a particular route. There are two particular nodes, which we will call A and B, and we will assume everyone wants to travel from A to B. Finally, each edge has a designated travel time that depends on the amount of traffic it contains. To make this concrete, consider the graph as a version of Braess's paradox. The label on each edge gives the travel time (in minutes) when there are $x$ carriers using the edge. In this simplified example, the A-D and $\mathrm{C}-\mathrm{B}$ edges are insensitive to congestion: Each takes $45 \mathrm{~min}$ to traverse regardless of the amount of traffic on them. On the other hand, the A-C and D-B edges are highly sensitive to congestion: For each one, it takes $x / 100$ min to traverse when there are $x$ carriers using the edge. Now, suppose that 4000 carriers want to get from A to B. There are two possible routes that each carrier can choose: The upper route through $\mathrm{C}$, or the lower route through D. For example, if each carrier takes the upper route (through $\mathrm{C}$ ), then the total travel time for everyone is $85 \mathrm{~min}$, since $4000 / 100+45=85$. The same is true if everyone takes the lower route. On the other hand, if the carriers divide up evenly between the two routes, thus that each carry 2000 units, then the total travel time on both routes is $2000 / 100+45=65$ [29].

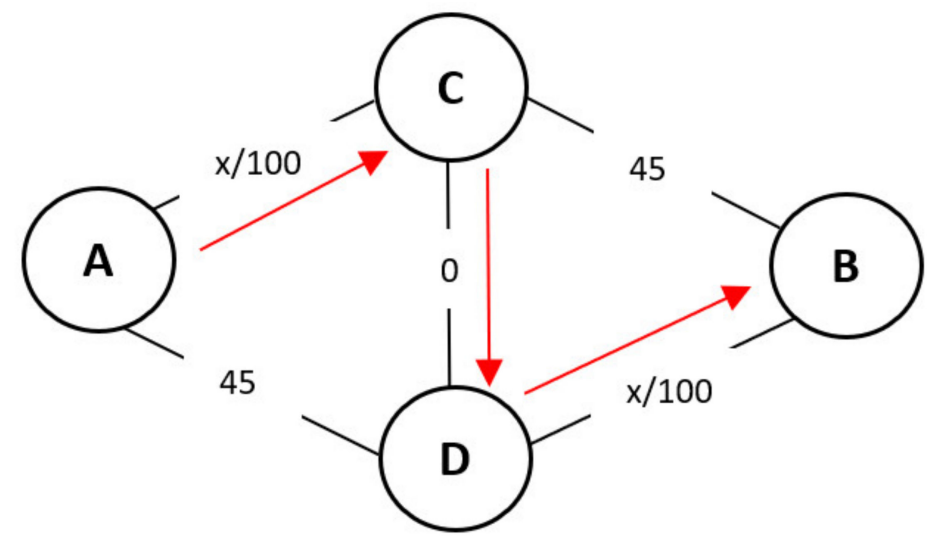

Figure 1. Version of the transport network and equilibrium route selection. Source: [29].

\subsection{Transformation of the Game from Normal to Extensive Form}

Simultaneous games shown in tabular or matrix form are called games in normal or strategic form. Let the game in normal form be shown in Table 2. Accordingly, two players who have two strategies at their disposal are playing a game, which is presented with the available strategies. Payments are functions of selected strategies shown in Equation (1) [15]:

$$
\left(a_{i j}, b_{i j}\right)=f\left(A_{i}, B_{j}\right)
$$

Table 2. The game in bimatric form.

\begin{tabular}{ccc}
\hline & $B_{1}$ & $B_{2}$ \\
\hline$A_{1}$ & $\left(\mathrm{a}_{11}, \mathrm{~b}_{11}\right)$ & $\left(\mathrm{a}_{12}, \mathrm{~b}_{12}\right)$ \\
$A_{2}$ & $\left(\mathrm{a}_{21}, \mathrm{~b}_{21}\right)$ & $\left(\mathrm{a}_{22}, \mathrm{~b}_{22}\right)$ \\
\hline
\end{tabular}


This game in extensive form is generated assuming the first player plays first. The game is shown in extensive form in Figure 2. First, the moves of the first player are presented, then the moves of the second player, final nodes, and payouts of the game are added as the end nodes.

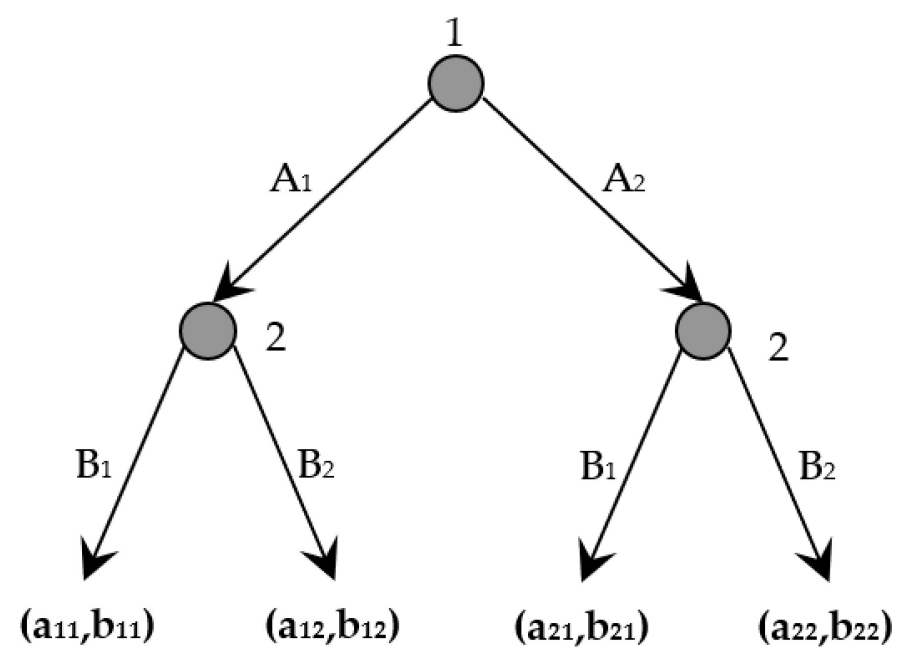

Figure 2. Game in extensive form. Source: [15].

Every final game of strategic (normal) form has an equilibrium mixed strategy. In the literature on Game Theory, this remained known as Nash equilibrium. Deviation of any player from the strategy contained in the concept of Nash's equilibrium cannot lead to an improvement in his position if other players adhere to their equilibrium strategies. Nash's equilibrium is reached by looking for the best response of each player to the given actions (strategies) of his opponents [15].

Drivers have no incentive to change their routes when making decisions [30]. If the system is not in a Nash equilibrium, selfish drivers must be able to improve their respective travel times by changing the routes they take [31]. In the case of Braess's paradox, drivers will continue to switch until they reach Nash equilibrium, despite the reduction in overall performance. If the latency functions are linear, then adding an upper value can never make total travel time at equilibrium worse by a factor of more than $\frac{4}{3}$ [32].

The problem can be introduced through the game-theoretic aspect by developing a transport network model and responding to traffic congestion. The directed graph represents a transport network: Considering the edges as roads (highways) and the nodes as exits where you can get on or off a particular road. Each edge has a designated travel time that depends on the amount of traffic it contains and transport costs [33].

\section{Coordinated Use of the Transport Network}

Game theory can be applied in a transport model where players correspond to the drivers and logistic operators. Each player's possible strategies consist of the possible routes from edge to edge. In more extensive networks, there could be many strategies for each player. The payoff for an individual player is negative when travel times are considered bad [33]. Independently operating carriers often achieve worse economic results than they would by forming a coalition with other carriers. In [34], with the Braess's paradox's help, losses incurred by the selfish or uncoordinated actions of participants on the transport network are described, known in the literature, as the "price of anarchy." There are numerous studies regarding the price of anarchy in logistics operators proving that rational moves can minimize the price of transport, reducing delivery time and carbon emissions [17-21].

To present the congestion game in this paper, the model of container transport costs of competing carriers on the transport network is observed (Figure 3). Carriers in terminals initialize the transport demand by making a freight delivery plan by booking the train 
route with the least number of stops or direct routes. If the train is at maximal load capacity, carriers can play the next move in choosing the route with minimal transport costs or equilibrium, where decreasing the cost is no longer possible. A rail route is selected if there is no congestion on the edges.

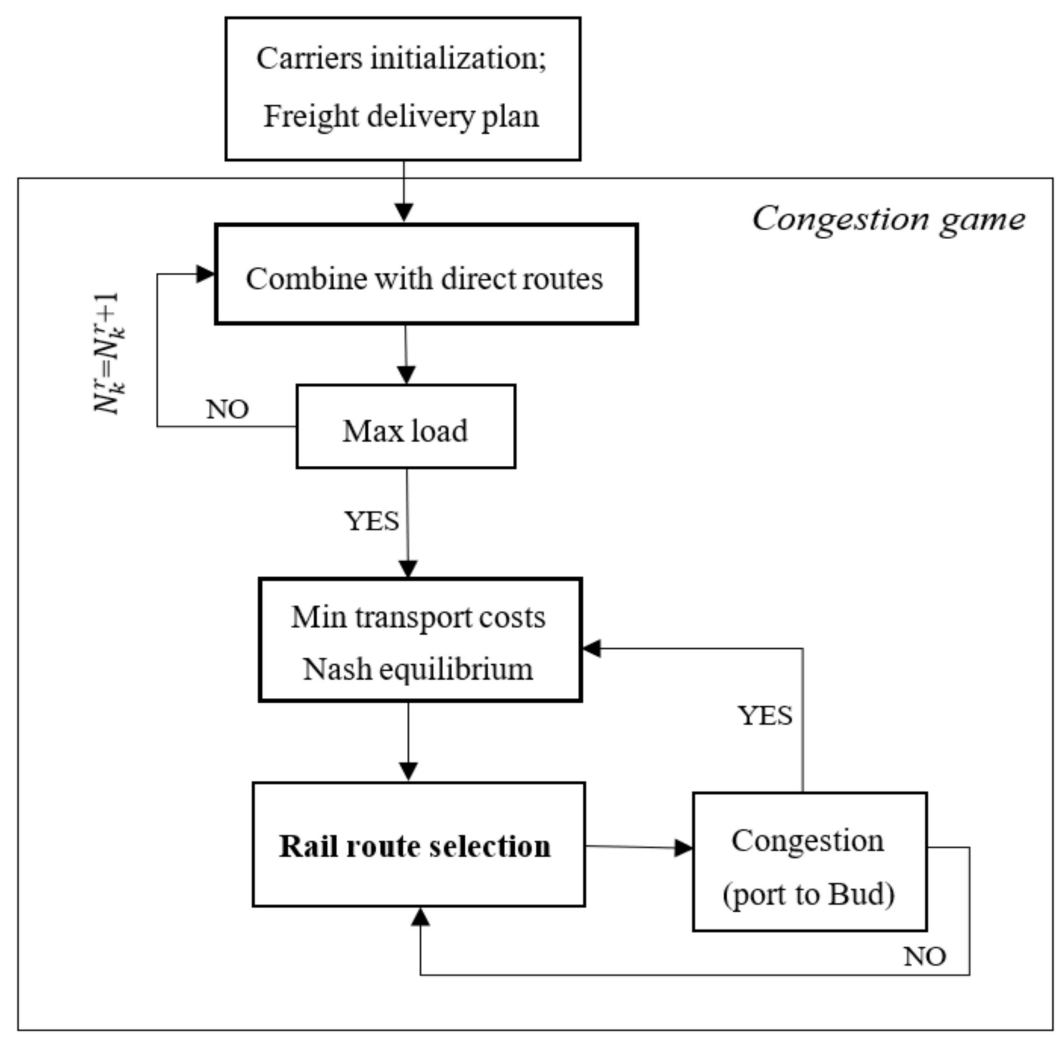

Figure 3. The framework of the decision-making process in intermodal network congestion game. Source: Authors.

The example of a railway network connecting three ports and the Budapest terminal must be described by the corridor's geographical and transport features with a certain level of intermodal integration of the network. Included infrastructure is located within the Mediterranean and Baltic-Adriatic Corridor and described with its handling characteristics in the paper's proceeding.

\subsection{Geographical Position and Berth Productivity of Ports}

The analyzed transport network is located on the Mediterranean Corridor, which is the central east-west axis in the Trans-European Transport Network (TEN-T) south of the Alps. The corridor primarily consists of road and rail, aside from the Po River, several canals in Northern Italy, and the Rhone River from Lyon to Marseille. The corridor is approximately $3000 \mathrm{~km}$ long and provides a multimodal link for the Western Mediterranean ports with the EU's center. It also creates an east-west link through the southern part of the EU, contributes to a modal shift from road to rail in sensitive areas such as the Pyrenees and the Alps, and connects some of the major urban areas of the EU with high-speed trains [34].

The Port of Trieste is in the Gulf of Trieste on the Adriatic coast in the coastal zone of the north-eastern part of the Adriatic. In Trieste, the main maritime longitudinal traffic route meets the land routes from Central Europe, or the Baltic-Adriatic and Mediterranean corridors, enabling the port's quality connection with other European cities through a single Trans-European network. More than 400 trains a month connect Trieste with the manufacturing and industrial areas of north-eastern Italy and Central Europe, with various destinations such as Germany, Austria, the Czech Republic, Hungary, Switzerland, and Luxembourg highly developed and organized hinterland. The good railway connection 
of Trieste with the hinterland of Europe has placed the port among the twenty strongest in Europe. The terminal's current capacity is 900,000 TEU units per $400,000 \mathrm{~m}^{2}$, allowing cargo flow growth without any risk of congestion or bottleneck formation [35].

The Port of Koper is the only Slovenian port of strategic interest, given that it is located on two Trans-European corridors, the Mediterranean and the Baltic-Adriatic corridor. The port is managed by "Luka Koper d.d.", a joint-stock company that manages and develops 12 specialized terminals. In 2018, the port achieved the best result in TEU units' trans-shipment compared to other northern Adriatic ports. The port handles the transshipment of all types of containers, and its success is greatly aided by regular rail links with the countries of Central and Eastern Europe. The terminal has regular weekly lines to the Far, Middle East, and the Red Sea and is connected via feeder service with important hub (consolidation) ports in the Mediterranean that have regular connections to all continents [36].

The Port of Rijeka is a port of special international importance and has the status of an open port for international and domestic public transport, which is of great economic importance for Croatia. The port is in the north of the Adriatic Sea in the Kvarner Bay and is the Mediterranean Corridor's main port. The port is connected to this corridor via the railway line Rijeka-Zagreb-Budapest. The Mediterranean Corridor is also connected by the route Zagreb-Zidani Most (Slovenia), through which the port of Rijeka can be connected to the Baltic-Adriatic Corridor. The Kvarner Bay is naturally sheltered from adverse weather conditions by large island series. The total turnover in the period from 2014 to 2018 increased by 4.8 million tons [37].

Considering the study of four Eastern Adriatic container terminals (CTs) shows that the terminals took different development decisions in the last decade. The Port of Koper significantly increased its throughput through minimal investment in berth lengthening and presently uses the shortest berth length among the four CTs. According to the compared data of global CTs (Table 3), this is a limiting element in further throughput increase, especially because two mother vessels (300 $\mathrm{m}$ in length) cannot be served simultaneously. In addition, the STS crane productivity of 12.22 TEU movements per hour is very high, and in case the terminal follows the strategy to supersede the early throughput of 1 to 1.2 million TEU, new investments in STS cranes will be necessary.

Table 3. Berth subsystem productivity increase of ports in 2006 and 2016.

\begin{tabular}{ccccc}
\hline $\begin{array}{c}\text { Seaport } \\
\text { Terminal }\end{array}$ & $\begin{array}{c}\text { Throughput } \\
\text { Change [TEU] }\end{array}$ & $\begin{array}{c}\text { Length Change } \\
{[\mathrm{m}]}\end{array}$ & $\begin{array}{c}\text { TEU/Berth Length } \\
{[\%]}\end{array}$ & $\begin{array}{c}\text { TEU/Crane } \\
\text { Hour [\%] }\end{array}$ \\
\hline Trieste & $+228,830$ & -650 & 275.66 & 103.70 \\
Koper ${ }^{1}$ & $+625,806$ & +146 & 191.29 & 92.90 \\
Rijeka & $+83,011$ & +159 & 40.36 & 87.94 \\
\hline
\end{tabular}

${ }^{1} 4$ new STS cranes. Source: [6].

The CT in Trieste made significant changes in terminal structure and technology. By this, the terminal is achieving significantly higher levels of productivity, but at the same time, it has margins for berth utilization and productivity increase. The difference is particularly evident in STS crane productivity. Installed capacity runs around $30 \%$ below the level on the same number of STS cranes. Consequently, the terminal has the infrastructure and superstructure for higher yearly throughput.

The CT in Rijeka has made important investments in the last 10 years, and the restructuring of the terminal is ongoing. With almost the same berth length as used by the Koper terminal, the terminal at Brajdica achieves three-times lower berth utilization. The number of STS cranes is in line with the average, but their productivity is about $20 \%$ lower. On this basis, the terminal has infrastructural and superstructural overcapacity, but a good basis for the throughput increase in the coming years should be the utilization of this terminal as the gateway for the Central European markets [6]. 


\subsection{Congestion Game in Selecting Railway Routes}

Through the specific example of rail cargo transport from three ports to a particular distribution center, it was shown that it is possible to find the lowest cost of transport per train on different routes for each freight carrier, considering terminal handling costs (THC) on the network. The data for THC values from all three ports were obtained by the port authorities, and the average value of all costs is $175 € / \mathrm{TEU}$, which is a constant value used in this case study because of the data confidentiality [35-37]. Game theory is used for analyzing possibilities, and the assumption is that players, or carriers, are not in complete conflict. In the process of determining routes, conflicts arise when a large number of transport network users create congestion using the same part of the transport network. Coordinated use of the transport network can relieve congested roads and increase overall flow by transferring to the railway, which results in a shorter total retention time for all network users or a reduction in total costs.

An example from three ports is observed: From Trieste, Koper, and Rijeka, cargo should be transported to the intermodal distribution center in Budapest. Figure 4 shows multiple connections between nodes on the transport network obtained from QGIS software, with added costs in euros per train, in which cargo is loaded in 20 equivalent unit (TEU) containers. Edges of the transport network are shown as straight lines as the network is intermodal, and the costs of transport and container handling are obtained by the intermodal terminals.

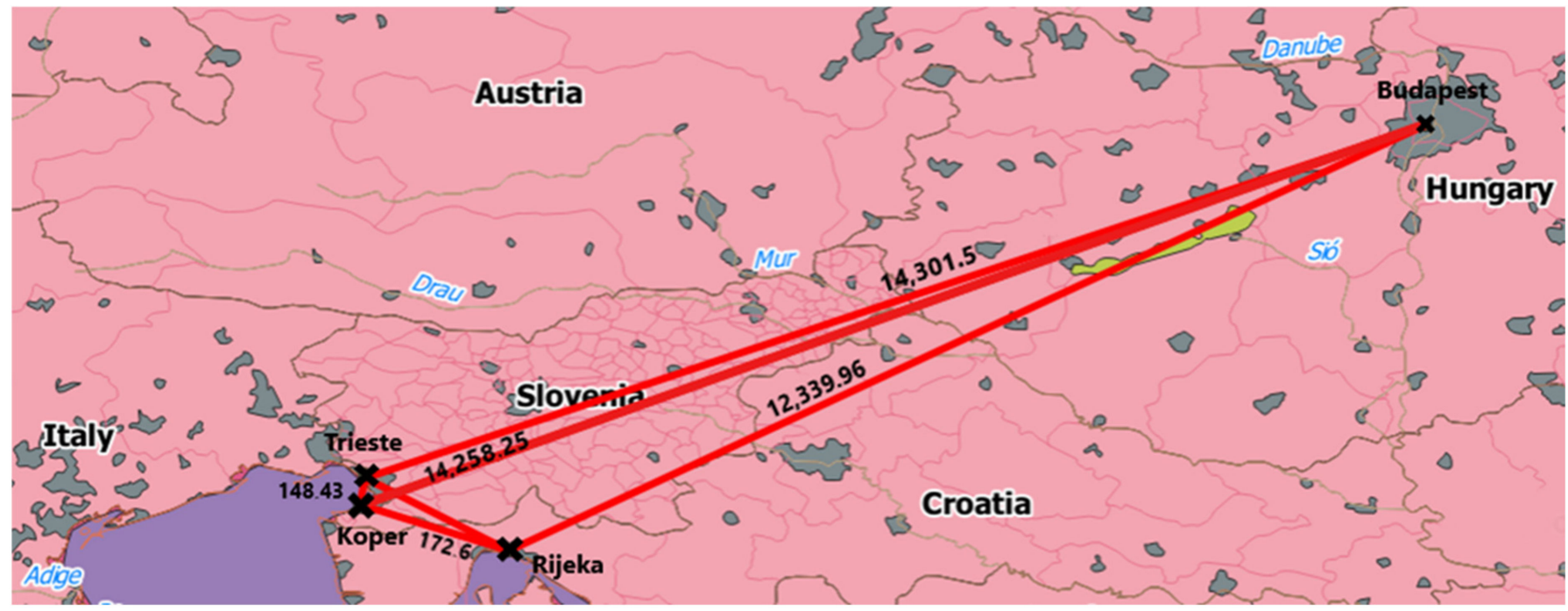

Figure 4. Congestion game-intermodal connections with appropriate costs [ $€ /$ train]. Source: Authors.

Using game theory as assumptions in calculating costs in railway transport is manifested as follows:

1. Congestion exists only on routes between ports and Budapest,

2. There is no congestion between ports,

3. Each transport on the route between port and Budapest is one player.

Therefore, Equation (2) shows the cost for players involved:

$$
C=c_{\text {trainkm }} \cdot l+T H C \cdot N_{k}^{r}\left[\frac{€}{\text { train }}\right]
$$

where is:

$c_{\text {trainkm }}$ - cost of train kilometer [ $€ /$ trainkm];

$l$-rail distance $[\mathrm{km}]$;

THC—-terminal handling cost [€/TEU]; 
$N_{k}^{t}$-number of containers per train [TEU/train].

With the following constraints:

$$
N_{k}^{r} \leq N_{k}^{\max }
$$

$N_{k}^{m a x}$-maximum number of containers per train [TEU];

$N_{k}^{r}$-real number of containers on a train [TEU].

In Table 4, certain parameters are shown, and it can be seen that the train costs per kilometer are the lowest from Koper regarding the total distance. Overall, the lowest transport costs are from Rijeka, but TEUs' maximal load per train is lower than on the other routes.

Table 4. A numerical example of the game parameters with a maximal load of the train.

\begin{tabular}{ccccc}
\hline Rail Route & $\begin{array}{c}\boldsymbol{C}_{\text {trainkm }} \\
{[\boldsymbol{\epsilon} / \text { train } \mathbf{~ k m}]}\end{array}$ & $\begin{array}{c}\boldsymbol{l} \\
{[\mathbf{k m}]}\end{array}$ & $\begin{array}{c}\text { THC } \\
{[\boldsymbol{\epsilon} / \text { TEU] }}\end{array}$ & $\begin{array}{c}\text { Max Load } \\
\text { [TEU/Train] }\end{array}$ \\
\hline Trieste-Budapest & 1.81 & 650 & 175 & 75 \\
Koper-Budapest & 1.75 & 663 & 175 & 75 \\
Rijeka-Budapest & 1.63 & 592 & 175 & 65 \\
\hline Source: $[38,39]$ & &
\end{tabular}
Source: [38,39].

Calculating the cost of transport between ports by rail, costs have the following values $[38,39]$ :

- $\quad$ Trieste-Koper $=148.43 €$;

- Koper-Rijeka $=172.60 €$.

Players are not in complete conflict, and their goal is to keep the total cost to a minimum. Since each player's starting points are not the same, the routes each can choose are different. The only criterion for selecting a route in the game from the example is the cost of transport, thus holding off is actually the cost of using that transport network. In the initial congestion game (Figure 5a), carriers from all three ports use Budapest's direct connections. Other scenario options are shown in Figure $5 b$,c. If the Trieste carrier sees the possibility of improvement as a cost reduction in the game, he will change the route through Rijeka. By changing his strategy, the Trieste carrier reduces its retention of decreasing costs, but in doing so, he increases the retention of the Rijeka carrier. The total cost of all three players in the congestion game, after the Trieste carrier's improved move, has increased, and it is called the price of anarchy-a cost incurred due to lack of coordination and selfish action by the players. A carrier from Koper can also see the possibility of cheaper transport via Rijeka. By changing its route, the Koper carrier increases transport costs to Trieste carriers to costs greater than Budapest's direct route. Therefore, Trieste players can improve their costs by reversing the strategy and choosing an initial, direct route to Budapest.

The problem can be seen as an extensive form of play. Each carrier chooses a logical strategy, which is shown in Figure 6.

In this state of the game, no carrier has the ability to cut costs by changing their route, thus the game is in Nash equilibrium. In addition, there is no combination of strategies where all players' total cost is less than the total cost in the Nash equilibrium, or in the case of a congestion game, there is no price of anarchy. There is no combination of choice of route for which the total cost would be less than $37,514 € /$ train. The Nash equilibrium is for the choice of route: Trieste-Koper-Rijeka-Budapest. 


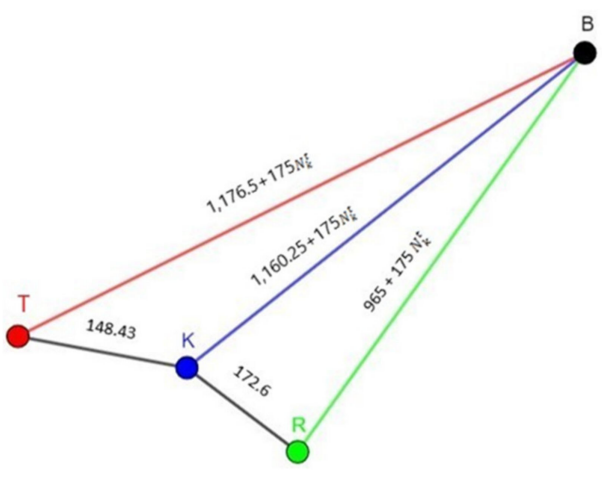

(a)

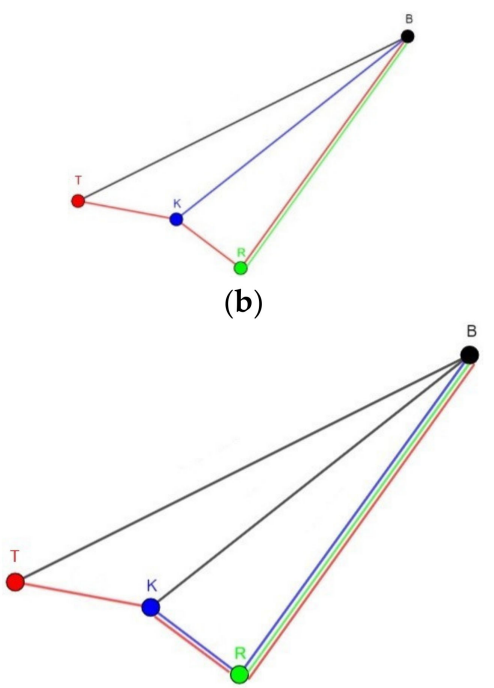

(c)

Figure 5. A second (a), third (b), and fourth (c) scenarios of route choice in a congestion game. Source: Authors.

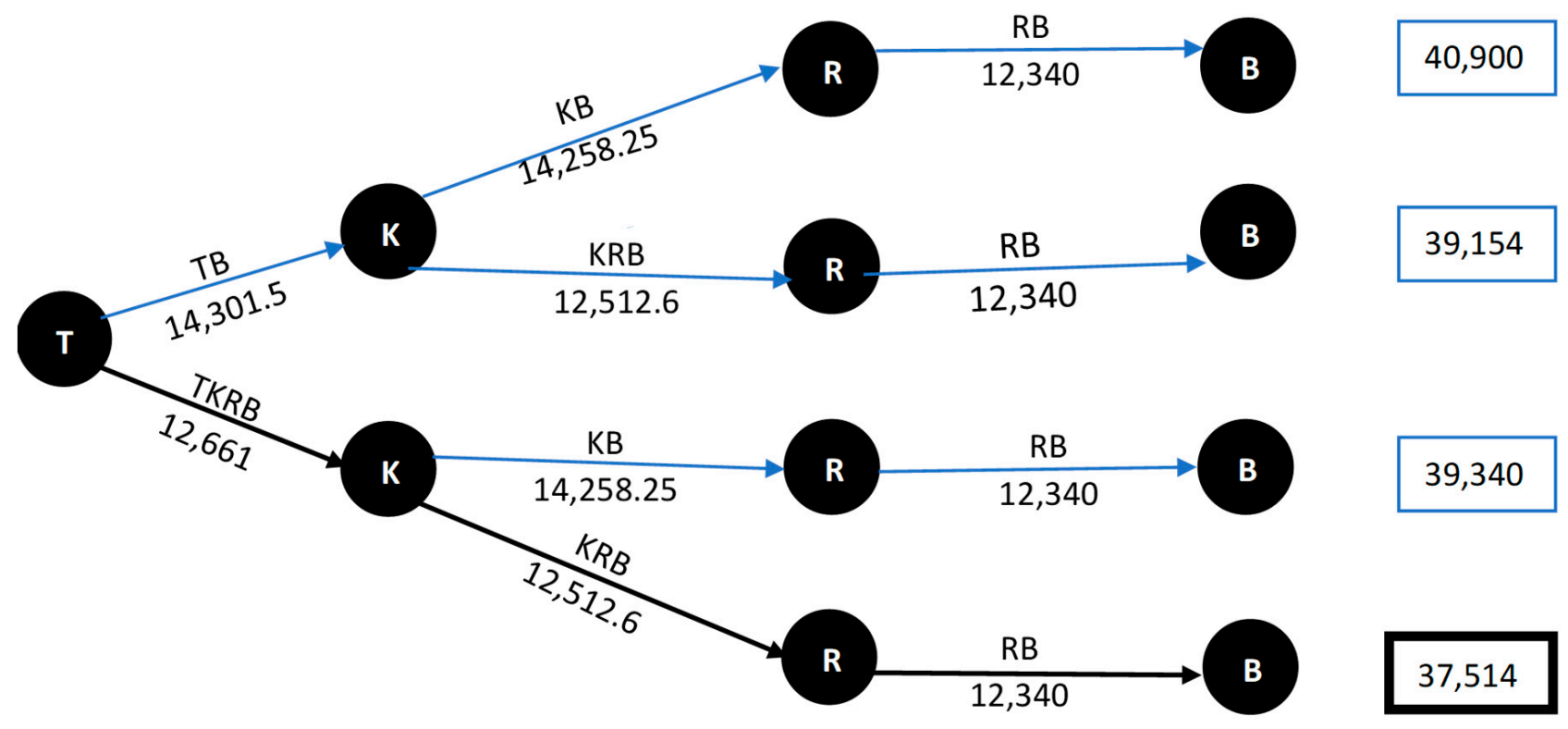

Figure 6. Extensive form of carrier game from Trieste, Koper, and Rijeka. Source: Authors.

\section{Discussion}

The proposed approach is illustrated with an example in which different cooperative game solution concepts are analyzed. Extensive numerical experiments have also been carried out to gain insight into the properties of the corresponding cost savings in congestion game and the behavior of the different players (carriers) transporting cargo by railway from seaports to Budapest intermodal terminal. Even though the connection from the port of Koper to Budapest has the lowest cost per train kilometer on the Budapest route, transport costs from Koper to Rijeka are higher than from Trieste to Koper. Comparing all possible route choices with reasonable costs by game theory approach, Nash equilibrium is in the lowest cost, but with a lower maximal load of TEUs on the train by which carriers should cooperate and transport the goods starting from the port of Trieste to the port of Koper, to the port of Rijeka, to Budapest terminal, resulting in decreasing costs of transport from $4.2 \%$ to $9.3 \%$. Smaller volume and more frequent transports coordinated network utilization and better cargo flow result in increased savings in transport costs, with removing road 
bottlenecks and congestions with a greener environmental impact. Future research should analyze the change in THC values, cost of the fees, and the maximum number of TEUs on the train. These elements are constants in this study because they appear in the 10-year data as the most common average value. Those values are otherwise variables, thus in further research, the direction is to conduct research with variable inputs when selecting routes. The game theory approach also suggests further research in decision-making processes and the use of the public transport network, connecting northern Adriatic ports with Eastern Europe, or serving as a transit point.

\section{Conclusions}

Game theory provides us with a powerful tool to think more clearly and reduce the number of scenarios to a rational scale, resulting in faster calculations. Analytical thinking is extremely useful in determining a set of reasonable possible outcomes. Game theory helps in making decisions that must result in an effective outcome. The strategy decision maker is rational and will always choose a rational outcome. The rational choice is the one that gives the most in a particular situation but by no means goes into the area of risk.

The paper points to some specifics of rational choice theory. A rational decision is not clear in itself, different decision-makers may perceive it differently. Rational decisionmaking also affects the psychological states of the decision-maker. The paper points to the example of the prisoner's dilemma that an individual's rational thinking does not lead to a Pareto effective outcome. It is recommended that the probability of a single decision is introduced in the payoff matrix. By using a combinatorial mechanism, it is analyzed whether collaboration partners are facing a Prisoner dilemma. This paper shows that independently from coalition partners' behavior, participants reduce their share of gained collaboration profits if they deviate from the jointly agreed selection rule.

Terminals have possibilities for berth utilization and productivity improvement without further investments in infrastructure and decreasing the THC. This is valid for the Trieste and Rijeka while the container terminal at Koper works at the upper limit, where further investments in berth extension and crane modernization are needed to maintain the positive trend of the yearly throughput increase.

It has been shown in the concrete example of freight transport that the coordinated use of the transport network leads to the minimization of the total costs. In the example shown, the carriers are trying to reduce their transport costs, but this leads them to "price of anarchy," and traffic congestion is created, resulting in an increase in the transport costs to all carriers. Applying game theory, all the players (the carriers) choose the only correct decision: The coordinated use of the transport network, in this case, the railway network. That is the optimal solution that gives the lowest cost to all carriers. In this example, irrespective of the player's initial irrationality, an equilibrium result can be achieved only through rational moves.

Author Contributions: Conceptualization, J.P.Š. and B.A.; formal analysis, L.B. and B.A.; funding acquisition, B.A.; investigation, V.Z.; methodology, V.Z.; resources, L.B.; validation, J.P.Š.; visualization, L.B. and V.Z.; writing-original draft preparation, L.B. and B.A.; writing-review and editing, J.P.Š., B.A. and V.Z. All authors have read and agreed to the published version of the manuscript.

Funding: This research received no external funding.

Institutional Review Board Statement: Not applicable.

Informed Consent Statement: Not applicable.

Data Availability Statement: Data sharing not applicable.

Acknowledgments: The research team would like to acknowledge the Port Authority of Rijeka, Koper and Trieste who supported the research with data contribution and materials used in study.

Conflicts of Interest: The authors declare no conflict of interest. 


\section{References}

1. Škrinjar, J.P.; Abramović, B.; Furdić, M. Methods of Bargaining in Logistics Processes. In Proceedings of the MATEC Web of Conferences, EDP Sciences, České Budějovice, Czech Republic, 19 October 2017; Volume 134, p. 00053. [CrossRef]

2. Nash, J.F. Equilibrium points in n-person games. Proc. Natl. Acad. Sci. USA 1950, 36, 48-49. [CrossRef] [PubMed]

3. Pašagić Škrinjar, J.; Abramović, B. Primjena teorije igara u prometu i logistici. Manualia Universitatis studiorum Zagrebiensis Croat. Sci. Bibliogr. 2017, 1, 186.

4. Harsanyi, J.C. Advances in Understanding Rational Behavior. In Essays on Ethics, Social Behavior, and Scientific Explanation; Springer: Dordrecht, The Netherlands, 1980; pp. 89-117.

5. Simon, H.A. Bounded Rationality and Organizational Learning. Organ. Sci. 1991, 2, 125-134. [CrossRef]

6. Beškovnik, B.; Twrdy, E.; Bauk, S. Developing Higher Berth Productivity: Comparison of Eastern Adriatic Container Terminals. Promet Traffic Transp. 2019, 31, 397-405. [CrossRef]

7. Pinakpani, P.; Polisetty, A.; Bhaskar, N.R.; BKumar, M.; Deepthi, D.; Sidhireddy, A. An Algorithmic Approach for Mari-time Transportation. Int. J. 2020, 11, 764-775.

8. Mahmoudi, R.; Shetab-Boushehri, S.-N.; Hejazi, S.R.; Emrouznejad, A.; Rajabi, P. A hybrid egalitarian bargaining game-DEA and sustainable network design approach for evaluating, selecting and scheduling urban road construction projects. Transp. Res. Part E Logist. Transp. Rev. 2019, 130, 161-183. [CrossRef]

9. Zhang, W.; Wang, X.; Yang, K. Incentive Contract Design for the Water-Rail-Road Intermodal Transportation with Travel Time Uncertainty: A Stackelberg Game Approach. Entropy 2019, 21, 161. [CrossRef]

10. Bekius, F.; Meijer, S.; De Bruijn, H. Collaboration patterns in the Dutch railway sector: Using game concepts to compare different outcomes in a unique development case. Res. Transp. Econ. 2018, 69, 360-368. [CrossRef]

11. Dogterom, N.; Ettema, D.; Dijst, M. Tradable credits for managing car travel: A review of empirical research and relevant behavioural approaches. Transp. Rev. 2017, 37, 322-343. [CrossRef]

12. Rizk, Y.; Awad, M.; Tunstel, E.W. Decision Making in Multiagent Systems: A Survey. IEEE Trans. Cogn. Dev. Syst. 2018, 10, 514-529. [CrossRef]

13. Butsenko, E. Optimization of Investment Planning Based on Game-Theoretic Approach. Econ. Reg. $2018,1,270-280$.

14. Huang, Z.X. Modeling bidding decision in engineering field with incomplete information: A static game-based approach. Adv. Mech. Eng. 2016, 8. [CrossRef]

15. Škrinjar, J.P.; Abramović, B.; Brnjac, N. The use of game theory in urban transport planning. Tech. Gaz. 2015, $22,1617-1621$. [CrossRef]

16. Hollander, Y.; Prashker, J.N. The applicability of non-cooperative game theory in transport analysis. Transportation 2006, 33, 481-496. [CrossRef]

17. Gansterer, M.; Hartl, R.F. The Prisoners' Dilemma in collaborative carriers' request selection. Cent. Eur. J. Oper. Res. 2021, $29,1-15$. [CrossRef]

18. Di Febbraro, A.; Sacco, N.; Saeednia, M. An agent-based framework for cooperative planning of intermodal freight transport chains. Transp. Res. Part C Emerg. Technol. 2016, 64, 72-85. [CrossRef]

19. Chen, H.; Lam, J.S.L.; Liu, N. Strategic investment in enhancing port-hinterland container transportation network resilience: A network game theory approach. Transp. Res. Part B Methodol. 2018, 111, 83-112. [CrossRef]

20. Khaslavskaya, A.; Roso, V. Dry ports: Research outcomes, trends, and future implications. Marit. Econ. Logist. 2020, 22, 265-292. [CrossRef]

21. Jamali, M.-B.; Rasti-Barzoki, M. A game theoretic approach to investigate the effects of third-party logistics in a sustainable supply chain by reducing delivery time and carbon emissions. J. Clean. Prod. 2019, 235, 636-652. [CrossRef]

22. Gilboa, I. Rational Choice; MIT Press: Cambridge, MA, USA, 2012.

23. Kopal, R.; Korkut, D. Teorija Igara: Praktična Primjena u Poslovanju; Comminus: Zagreb, Croatia, 2011.

24. Sys, C.; Blauwens, G.; Omey, E.; van de Voorde, E.; Witlox, F. In Search of the Link between Ship Size and Operations. Transp. Plan. Technol. 2008, 31, 435-463. [CrossRef]

25. Kim, K.H.; Lee, H. Container Terminal Operation: Current Trends and Future Challenges. In Handbook of Ocean Container Transport Logistics; Lee, C.Y., Meng, Q., Eds.; Springer International Publishing: Cham, Switzerland, 2015.

26. Kahneman, D. Prospect theory: An analysis of decisions under risk. Econometrica 1979, 47, 278. [CrossRef]

27. Braess, D. Über ein Paradoxon aus der Verkehrsplanung. Math. Methods Oper. Res. 1968, 12, 258-268. [CrossRef]

28. Nagurney, A. The negation of the Braess paradox as demand increases: The wisdom of crowds in transportation net-works. EPL Europhys. Lett. 2010, 91, 48002. [CrossRef]

29. Easley, D.; Kleinberg, J. Networks, Crowds, and Markets: Reasoning about a Highly Connected World: Book; Cambridge University Press: Cambridge, UK, 2010; Chapter 8.

30. Chung, F.; Young, S.J. Braess's paradox in large sparse graphs. In Proceedings of the International Workshop on Internet and Network Economics, Stanford, CA, USA, 13-17 December 2010; Springer: Berlin, Germany, 2010; pp. $194-208$.

31. Lin, H.; Roughgarden, T.; Tardos, É.; Walkover, A. Stronger Bounds on Braess's Paradox and the Maximum Latency of Selfish Routing. SIAM J. Discret. Math. 2011, 25, 1667-1686. [CrossRef] 
32. Pala, M.G.; Baltazar, S.; Liu, P.; Sellier, H.; Hackens, B.; Martins, F.; Bayot, V.; Wallart, X.; Desplanque, L.; Huant, S. Transport Inefficiency in Branched-Out Mesoscopic Networks: An Analog of the Braess Paradox. Phys. Rev. Lett. 2012, 108, 076802. [CrossRef] [PubMed]

33. Cardenete, M.; López-Cabaco, R. Economic and Environmental Impact of the New Mediterranean Rail Corridor in Andalusia: A Dynamic CGE Approach. Transp. Policy 2021, 102, 25-34. [CrossRef]

34. Ilak, A. Određivanje Prijevoznih Ruta Primjenom Teorije Igara. Master's Thesis, Faculty of Transport and Traffic Sciences, University of Zagreb, Zagreb, Croatia, 25 September 2019.

35. Official Web Page of Port of Koper. Available online: https://www.luka-kp.si (accessed on 1 March 2021).

36. Official Web Page of Port of Trieste. Available online: https://www.porto.trieste.it (accessed on 1 March 2021).

37. Official Web Page of Port of Rijeka. Available online: https://lukarijeka.hr/financijska-izvjesca/ (accessed on 1 March 2021).

38. Ribarić, M. Usporedna Analiza Prijevoznih Robnih Pravca na Relaciji Sjeverojadranske Luke-Žilina. Master's Thesis, Faculty of Transport and Traffic Sciences, University of Zagreb, Zagreb, Croatia, 23 September 2019.

39. Dokoza, M. Benchmarking Pristojbi za Željezničku Infrastrukturu u Srednjoj Europi. Master's Thesis, Faculty of Transport and Traffic Sciences, University of Zagreb, Zagreb, Croatia, 10 July 2018. 